\title{
Antithrombin III is associated with acute liver failure in patients with end-stage heart failure undergoing mechanical circulatory support
}

\author{
Judith Hoefer, MD, ${ }^{\mathrm{a}}$ Hanno Ulmer, PhD, ${ }^{\mathrm{b}}$ Juliane Kilo, MD, ${ }^{\mathrm{c}}$ Raimund Margreiter, MD, ${ }^{\mathrm{d}}$ \\ Michael Grimm, MD, ${ }^{\mathrm{a}}$ Peter Mair, MD, ${ }^{\mathrm{a}}$ and Elfriede Ruttmann, $\mathrm{MD},{ }^{\mathrm{c}}$ on behalf of the Innsbruck \\ Liver-in-Heart-Failure Program
}

\begin{abstract}
Objective: There are few data on the role of liver dysfunction in patients with end-stage heart failure supported by mechanical circulatory support. The aim of our study was to investigate predictors for acute liver failure in patients with end-stage heart failure undergoing mechanical circulatory support.

Methods: A consecutive 164 patients with heart failure with New York Heart Association class IV undergoing mechanical circulatory support were investigated for acute liver failure using the King's College criteria. Clinical characteristics of heart failure together with hemodynamic and laboratory values were analyzed by logistic regression.
\end{abstract}

Results: A total of 45 patients (27.4\%) with heart failure developed subsequent acute liver failure with a hospital mortality of $88.9 \%$. Duration of heart failure, cause, cardiopulmonary resuscitation, use of vasopressors, central venous pressure, pulmonary capillary wedge pressure, pulmonary pulsatility index, cardiac index, and transaminases were not significantly associated with acute liver failure. Repeated decompensation, atrial fibrillation $(P<.001)$ and the use of inotropes $(P=.007)$, mean arterial $(P=.005)$ and pulmonary pressures $(P=.042)$, cholinesterase, international normalized ratio, bilirubin, lactate, and $\mathrm{pH}(P<.001)$ were predictive of acute liver failure in univariate analysis only. In multivariable analysis, decreased antithrombin III was the strongest single measurement indicating acute liver failure (relative risk per $\%, 0.84 ; 95 \%$ confidence interval, $0.77-0.93$; $P=.001$ ) and remained an independent predictor when adjustment for the Model for End-Stage Liver Disease score was performed (relative risk per \%, 0.89; 95\% confidence interval, $0.80-0.99 ; P=.031$ ). Antithrombin III less than $59.5 \%$ was identified as a cutoff value to predict acute liver failure with a corresponding sensitivity of $81 \%$ and specificity of $87 \%$.

Conclusions: In addition to the Model for End-Stage Liver Disease score, decreased antithrombin III activity tends to be superior in predicting acute liver failure compared with traditionally thought predictors. Antithrombin III measurement may help to identify patients more precisely who are developing acute liver failure during mechanical circulatory support. (J Thorac Cardiovasc Surg 2017;153:1374-82)

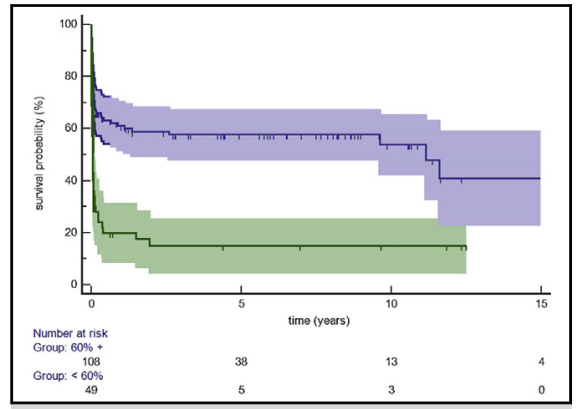

Survival after MCS in accordance to antithrombin III cutoff levels $(<60 \%)$ before MCS implementation.

\section{Central Message}

Antithrombin III measurement is associated with the hepatic reserve in patients requiring MCS.

\section{Perspective}

Development of irreversible ALF in patients in cardiogenic shock during MCS is associated with poor outcome and is limiting the full potential that MCS therapy has to offer. The result of this study demonstrates that additional surveillance measurement of antithrombin III is a strong prognostic parameter to predict hepatic functional reserve in patients undergoing MCS and may help to decide the optimal timing of MCS.

\section{See Editorial Commentary page 1383.}

See Editorial page 1373 .
From the Departments of anesthesiology and Intensive Care Medicine, ${ }^{\mathrm{b}}$ Medical Statistics, Informatics, and Health Economics, ${ }^{\mathrm{c} C a r d i a c}$ Surgery, and ${ }^{\mathrm{d}}$ Visceral, Transplant and Thoracic Surgery, Innsbruck Medical University, Innsbruck, Austria.

Received for publication Aug 8, 2016; revisions received Dec 19, 2016; accepted for publication Jan 19, 2017; available ahead of print March 6, 2017.
Address for reprints: Elfriede Ruttmann, MD, Department of Cardiac Surgery, Innsbruck Medical University, Anichstrasse 35, 6020 Innsbruck, Austria (E-mail: elfriede.ruttmann@i-med.ac.at).

$0022-5223 / \$ 36.00$

Copyright (C) 2017 by The American Association for Thoracic Surgery

http://dx.doi.org/10.1016/j.jtcvs.2017.01.053 

Abbreviations and Acronyms
$\mathrm{ALF}=$ acute liver failure
$\mathrm{CI}=$ confidence interval
$\mathrm{ECMO}=$ extracorporeal membrane oxygenation
$\mathrm{HF}=$ heart failure
INR = international normalized ratio
MCS = mechanical circulatory support
MELD $=$ Model for End-Stage Liver Disease
$\mathrm{RR} \quad=$ relative risk $\begin{aligned} \text { SIRS }= & \text { systemic inflammatory response } \\ \text { syndrome } & \end{aligned}$

Scanning this QR code will take you to a supplemental video for the article.

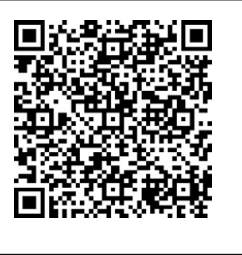

The number of patients requiring mechanical circulatory support (MCS) is increasing rapidly and consistently despite ongoing advances in the medical management of end-stage heart failure (HF). ${ }^{1}$ MCS, by extracorporeal membrane oxygenation (ECMO) or ventricular assist devices, has become a mainstay of management strategy for patients with end-stage $\mathrm{HF}^{2,3}$ Consequently, there is an increasing proportion of patients being considered for MCS who may have underlying renal or hepatic dysfunction. $^{2-5}$

After stabilization of hemodynamics and restoration of sufficient cardiac output by MCS, preexisting concomitant multiorgan dysfunction often is associated with poor outcome and limiting the full potential that MCS therapies has to offer. ${ }^{1,2}$

The cardiorenal syndrome, affecting one third of patients with decompensated HF, has been intensely investigated, and strategies such as ultrafiltration have been suggested to slow down the progression of $\mathrm{HF}^{5,6}$ Recent prospective randomized data have questioned the efficacy of ultrafiltration. To the contrary, a higher rate of severe adverse events has been associated with its use compared with diuretic therapy alone. ${ }^{7}$

The role of the liver in acute and chronic HF has not been systematically investigated, probably because of complex dual blood supply, and irreversible liver damage may be the result of both "backward" congestion and "antegrade" ischemic mechanism. 8

Development of acute liver failure (ALF) in patients with acute and chronic HF is a frequently observed complication after implementation of MCS, and currently there is a lack of clinical data and evidence to indicate "point of no return" when irreversible liver failure develops. The aim of the current investigation was to identify independent risk factors for ALF in patients with end-stage HF in American College of Cardiology/American Heart Association stage D undergoing MCS.

\section{MATERIALS AND METHODS}

All consecutive patients, aged 12 years or older, who were admitted to our department from 2000 to 2016, and who received MCS by venoarterial ECMO as first-line treatment for acute or chronic HF in New York Heart Association functional class IV and American College of Cardiology/ American Heart Association stage D constituted the study population.

Inclusion criteria were all forms of cardiogenic shock in patients not being connected to MCS devices or extracorporeal circulation before.

Exclusion criteria were "postcardiotomy" failure, that is, patients receiving ECMO or ventricular assist device as a result of failure to separate from cardiopulmonary bypass or postcardiac surgery HF within 1 month ( $\mathrm{n}=202$ patients) and patients with hypothermic cardiac arrest undergoing ECMO-assisted resuscitation ( $\mathrm{n}=45$ patients). In addition, patients receiving venovenous ECMO for respiratory failure alone were excluded $(\mathrm{n}=101$ patients). Video 1 shows open surgical implementation of femoral extracorporeal membrane oxygenation.

The cause of HF was defined as ischemic, either chronic ischemic cardiomyopathy or acute ischemic HF with cardiogenic shock and nonischemic cardiac failure (chronic dilative cardiomyopathy, hypertrophic cardiomyopathy, or acute myocarditis).

The cause, duration, history, and number of decompensation events of patients with HF were documented and classified. Hemodynamic and laboratory parameters were assessed after the patient was taken to the operating room immediately before heparinization and the onset of venoarterial ECMO flow. The study was approved by the local institutional review board.

\section{King's College Criteria}

The King's College Criteria were used to define the primary end point of development of ALF during MCS. ${ }^{10}$ These criteria were devised in 1989 to determine early indices of poor prognosis in patients with acetaminopheninduced and nonacetaminophen-induced ALF. For this study, the criteria of nonacetaminophen-induced ALF were used to determine the primary

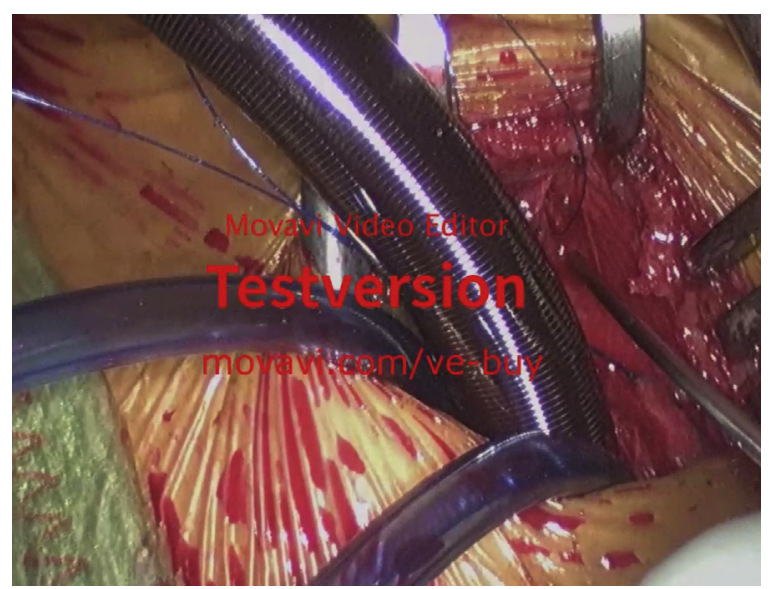

VIDEO 1. Open femoral implantation of venoarterial ECMO. Video available at: http://www.jtcvsonline.org/article/S0022-5223(17)30203-9/ addons. 
outcome of this study. Currently, there is no specific definition for cardiacrelated ALF available. Therefore, the King's College criteria were adopted to indicate ALF development after initiation of MCS. ALF was defined as spontaneous international normalized ratio (INR) greater than 6.5 or at least 3 of the following criteria:

1. patient age less than 11 years or more than 40 years;

2. serum creatinine greater than $3.4 \mathrm{mg} / \mathrm{dL}$ or new institution of ultrafiltration/hemodialysis;

3. time from onset of jaundice to the development of coma of more than 7 days;

4. spontaneous INR more than 3.5 ;

5. drug toxicity, regardless of whether it was the cause of ALF;

6. serum bilirubin greater than $300 \mu \mathrm{m} / \mathrm{L}(>17.6 \mathrm{mg} / \mathrm{dL})$;

7. presence of coagulopathy.

\section{Statistical Analysis}

The development of ALF during mechanical bridging served as the primary end point of our study. Data are shown as mean \pm standard deviation or median (range) for continuous variables and absolute numbers, as well as percentages for categoric variables.

Survival of the patients was displayed using a Kaplan-Meier survival plot together with log-rank testing. In a first step, possible associations of ALF with clinical, hemodynamic, and laboratory parameters at the time of mechanical bridging onset together with a history of HF were assessed by means of univariate analysis. To test for univariate differences in categoric variables, the Pearson chi-square test or Fisher exact test where appropriate was applied. Continuous variables were tested with the Student $t$ test or Mann-Whitney $U$ test (if assumption of a Gaussian distribution was not fulfilled).

In a second step, multivariable logistic regression analysis was performed to identify independent predictors for the development of ALF. The relative risk (RR) and 95\% confidence intervals (CIs) were determined. The selection of variables was based on univariate comparisons (entry criteria $P<.05$ ) and inclusion of clinically relevant variables to create the model of logistic regression. The Wald statistic was used to assess the strength of the association of risk factors relative to other risk factors.

Finally, we performed receiver operating characteristic analysis to identify cutoff values for liver-specific predictors together with corresponding sensitivity and specificity. Data documentation and statistical analysis were performed with SPSS statistical software version 20.0 (IBM SPPS Inc, New York, NY).

\section{RESULTS}

A total of 164 patients with end-stage HF fulfilled the inclusion criteria of our study; of them, 45 patients $(27.4 \%)$ developed ALF during MCS. In-hospital mortality was significantly higher among patients developing ALF during mechanical bridging therapy $(35.3 \%$ vs $88.9 \%, P<.001)$.

Table 1 displays the demographic characteristics of patients undergoing mechanical bridging stratified for ALF. Patients were comparable in terms of gender, age, body mass index, or the cause of HF. However, patients developing ALF showed a higher rate of previous repeated cardiac decompensation events compared with patients without $\operatorname{ALF}(P=.001)$. Patients with ALF had significantly higher creatinine levels $(1.4 \pm 0.8 \mathrm{mg} / \mathrm{dL}$ vs $1.9 \pm 0.76 \mathrm{mg} / \mathrm{dL}, P<.001$ ), had a higher rate of previous episode of renal failure $(0.8 \%$ vs $24.4 \%, P<.001)$, and were significantly more likely to be undergoing hemofiltration at the onset of MCS $(6.7 \%$ vs $68.9 \%, P<.001)$. Furthermore, atrial fibrillation at the time of MCS onset was more prevalent in patients developing ALF (12.6\% vs $37.8 \%, P<.001)$.

Table 2 shows the hemodynamic and laboratory parameters of the study population immediately before the implementation of MCS.

Patients developing ALF demonstrated lower $\mathrm{pH}$ $(7.35 \pm 0.10$ vs $7.27 \pm 0.13, P=.001)$, higher lactate $(42.9 \pm 41.7 \mathrm{mg} / \mathrm{dL}$ vs $69.8 \pm 49.2 \mathrm{mg} / \mathrm{dL}, P<.001)$, and significantly elevated total bilirubin levels $(1.4 \pm 1.2 \mathrm{mg} / \mathrm{dL}$ vs $4.0 \pm 3.7 \mathrm{mg} / \mathrm{dL}, P<.001)$. Cholinesterase $(4.54 \pm 1.81 \mathrm{mg} / \mathrm{dL}$ vs $2.62 \pm 1.32 \mathrm{mg} / \mathrm{dL}, P<.001)$ and antithrombin III activity $(75.1 \% \pm 14.8 \%$ vs $51.8 \% \pm 10.4 \%, P<.001)$ were significantly lower in patients developing subsequent ALF. Spontaneous INR was higher in patients developing ALF $(1.36 \pm 0.31$ vs $1.74 \pm 0.60, P<.001)$. In addition, calculated Model for End-Stage Liver Disease (MELD) scores were significantly higher in patients developing later ALF $(12.0 \pm 4.0$ vs $24.4 \pm 6.7 ; P<.001)$.

Moreover, patients developing ALF showed higher mean pulmonary pressure $(29.3 \pm 9.9 \mathrm{~mm} \mathrm{Hg}$ vs $33.1 \pm 10.4 \mathrm{~mm}$ $\mathrm{Hg}, P=.042)$ and significantly lower mean arterial pressure $(67.0 \pm 12.0 \mathrm{~mm} \mathrm{Hg}$ vs $61.1 \pm 11.9 \mathrm{~mm} \mathrm{Hg}, P=.005)$. There were no statistical differences between central venous pressures and pulmonary capillary wedge pressures at the time of mechanical bridging initiation. The use and dosage of vasopressors were similar among both groups. The use of inotropes before bridging was more frequent in patients with latter development of ALF $(57.1 \%$ vs $80.0 \%, P=.007)$.

Table 3 shows the result of the multivariable statistical analysis. Hemodynamic parameters at the time of MCS onset were not associated with the development of ALF, nor the use of inotropic medication. Renal failure with the need for hemofiltration before MCS was a strong independent predictor for subsequent ALF (Wald, 4.7; RR, 8.6; 95\% CI, 1.2-61.2, $P=.031$ ). Furthermore, a history of repeated cardiac decompensation events (Wald, 4.0; RR, 6.7; 95\% CI, 1.1-43.0; $P=.046)$ was associated with ALF.

However, decreased antithrombin III activity (Wald: 11.8 , RR per $\%: 0.84,95 \%$ CI, 0.77-0.93, $P=.001$ ) was the strongest independent parameter for the development of ALF during MCS. Other hemodynamic and laboratory parameters failed to show statistically significant influence for ALF.

Table 4 displays the result of the multivariate regression analysis including the MELD score instead of its components. Again, antithrombin III remained an independent clinical parameter for the development of ALF in addition to the MELD score. 
TABLE 1. Demographic characteristics of patients undergoing mechanical circulatory support by venoarterial extracorporeal membrane oxygenation support

\begin{tabular}{|c|c|c|c|}
\hline & $\begin{array}{c}\text { No liver failure } \\
\text { (n=119 patients) }\end{array}$ & $\begin{array}{c}\text { ALF } \\
(n=45 \text { patients })\end{array}$ & $P$ value \\
\hline Male gender $(\%)$ & $86(72.3 \%)$ & $31(68.9 \%)$ & .67 \\
\hline Age, y $($ mean \pm SD) & $49.2 \pm 15$ & $52.2 \pm 12.9$ & .26 \\
\hline BMI $\left(\mathrm{kg} / \mathrm{m}^{2}\right)$ & $24.6 \pm 4.1$ & $25.4 \pm 3.1$ & .24 \\
\hline \multicolumn{4}{|l|}{ BMI class } \\
\hline Normal $(<25)$ & $71(59.7 \%)$ & $19(42.2 \%)$ & \\
\hline Overweight $(25-<30)$ & $40(33.6 \%)$ & $23(51.1 \%)$ & \\
\hline Obese $(30+)$ & $8(6.7 \%)$ & $3(6.7 \%)$ & .11 \\
\hline \multicolumn{4}{|l|}{ Cause of HF } \\
\hline Acute ischemic & $39(32.8 \%)$ & $13(28.9 \%)$ & \\
\hline Chronic ischemic & $21(17.6 \%)$ & $8(17.8 \%)$ & \\
\hline Acute nonischemic & $25(21.0 \%)$ & $8(17.7 \%)$ & \\
\hline Chronic nonischemic & $34(28.6 \%)$ & $16(35.6 \%)$ & .84 \\
\hline \multicolumn{4}{|l|}{ No. of decompensation events } \\
\hline None & $15(12.6 \%)$ & $2(4.4 \%)$ & \\
\hline First decompensation event & $85(71.5 \%)$ & $22(48.9 \%)$ & \\
\hline Second decompensation event & $4(3.3 \%)$ & $3(6.7 \%)$ & \\
\hline Repeated decompensation event & $15(12.6 \%)$ & $18(40.0 \%)$ & .001 \\
\hline Creatinine at mechanical bridging onset (mg/dL) & $1.4 \pm 0.80$ & $1.9 \pm 0.76$ & $<.001$ \\
\hline \multicolumn{4}{|l|}{ Previous events of renal failure } \\
\hline Chronic hemodialysis & $1(0.8 \%)$ & $1(2.2 \%)$ & \\
\hline Previous events with renal failure & $1(0.8 \%)$ & $11(24.4 \%)$ & $<.001$ \\
\hline Need for hemofiltration/hemodialysis & $8(6.7 \%)$ & $31(68.9 \%)$ & $<.001$ \\
\hline Previous cardiopulmonary resuscitation & $42(35.3 \%)$ & $9(20.0 \%)$ & .06 \\
\hline Device implant under cardiopulmonary resuscitation & $10(8.4 \%)$ & $4(8.9 \%)$ & .92 \\
\hline History of cardiac surgery & $8(6.7 \%)$ & $6(13.3 \%)$ & .18 \\
\hline Previous PCI & $29(24.4 \%)$ & $11(24.4 \%)$ & .34 \\
\hline Atrial fibrillation & $15(12.6 \%)$ & $17(37.8 \%)$ & $<.001$ \\
\hline Cardiac resynchronization pacemaker & $3(2.5 \%)$ & $0(0 \%)$ & \\
\hline \multicolumn{4}{|l|}{$\mathrm{ICD}$} \\
\hline CRT & $6(5 \%)$ & $6(13 \%)$ & \\
\hline Non-CRT ICD & $14(11.8 \%)$ & $2(4.4 \%)$ & .11 \\
\hline ECMO only & $49(41.2 \%)$ & $21(46.7 \%)$ & \\
\hline ECMO and consecutive ventricular assist device & $29(24.4 \%)$ & $14(31.1 \%)$ & .29 \\
\hline
\end{tabular}

Bold indicates that patients who developed ALF were significantly more likely to have repeated decompensation events, higher creatinine levels, previous renal failure, and atrial fibrillation at mechanical circulatory support onset. $A L F$, Acute liver failure; $S D$, standard deviation; $B M I$, body mass index; $H F$, heart failure; $P C I$, percutaneous coronary intervention; $I C D$, implantable cardioverter defibrillator; $C R T$, cardiac resynchronization therapy; $E C M O$, extracorporeal membrane oxygenation.

Furthermore, because antithrombin III turned out to be the most predictive single measure for ALF, receiver operating characteristic analysis was performed to obtain cutoff levels for these predictors and evaluate the sensitivity and specificity of this parameter as an early indicator for ALF. In addition, this analysis was performed for the MELD score. Antithrombin III activity levels of $59.5 \%$ or less were identified as cutoff values to predict an increased risk for ALF (RR, 9.8; 95\% CI, 5.1-20.3; $P<.001$ ). Corresponding sensitivity was $81 \%(95 \% \mathrm{CI}, 0.67-0.91)$ and specificity of $87 \%(95 \% \mathrm{CI}, 0.80-0.93)$ with a positive predictive value of $72 \%$.

A MELD score greater than 17 at MCS onset was associated with $88.9 \%$ sensitivity $(95 \%$ CI, 0.76-0.96) and $93.3 \%$ specificity $(95 \% \mathrm{CI}, 0.87-0.97)$ with a positive predictive value of $83.3 \%$.
As a consequence, Kaplan-Meier analysis was performed to obtain the long-term survival of patients with end-stage HF stratified for antithrombin III cutoff levels (Figure 1). Actuarial survival at 1,5 , and 10 years after MCS onset was $20 \%, 15 \%$, and $15 \%$ in patients with HF with antithrombin levels less than $60 \%$ and $61.1 \%$, $58.9 \%$, and $54.9 \%$, respectively, in patients with antithrombin activity of at least $60 \%$ at baseline (log-rank: $P<.001)$. Figure 2 displays the survival plot for patients with MELD scores of less than and greater than 17 .

\section{DISCUSSION}

The results of our study clearly demonstrate that antithrombin III is a strong independent prognostic single measure to predict hepatic functional reserve in patients with end-stage $\mathrm{HF}$ resistant to conservative medical treatment. 
TABLE 2. Intraoperative laboratory and hemodynamic parameters before mechanical circulatory support by venoarterial extracorporeal membrane oxygenation

\begin{tabular}{|c|c|c|c|}
\hline & $\begin{array}{c}\text { No liver failure } \\
(\mathrm{n}=119 \text { patients })\end{array}$ & $\begin{array}{c}\mathbf{A L F} \\
(\mathrm{n}=\mathbf{4 5} \text { patients })\end{array}$ & $P$ value \\
\hline $\mathrm{pH}$ & $7.35 \pm 0.10$ & $7.27 \pm 0.13$ & .001 \\
\hline Lactate (mg/dL) & $42.9 \pm 41.7$ & $69.9 \pm 49.2$ & $<.001$ \\
\hline Bilirubin $(\mathrm{mg} / \mathrm{dL})$ & $1.4 \pm 1.2$ & $4.0 \pm 3.7$ & $<.001$ \\
\hline MELD score & $12.0 \pm 4.0$ & $24.4 \pm 6.7$ & $<.001$ \\
\hline Total protein (g/dL) & $6.0 \pm 1.1$ & $5.7 \pm 1.4$ & .26 \\
\hline Potassium (mmol/L) & $4.14 \pm 0.8$ & $4.2 \pm 0.9$ & .51 \\
\hline Sodium $(\mathrm{mmol} / \mathrm{L})$ & $139.6 \pm 7.7$ & $140.6 \pm 8.8$ & .48 \\
\hline Chloride (mmol/L) & $101.3 \pm 7.6$ & $101.0 \pm 6.4$ & .77 \\
\hline Magnesium (mmol/L) & $0.92 \pm 0.24$ & $0.97 \pm 0.33$ & .33 \\
\hline Anorganic phosphate $(\mathrm{mmol} / \mathrm{L})$ & $1.42 \pm 0.54$ & $0.99 \pm 0.74$ & .65 \\
\hline Amylase (U/L) & $50.0 \pm 14.9$ & $49.2 \pm 15.8$ & .93 \\
\hline Lipase (U/L) & $53.3 \pm 23.1$ & $54.2 \pm 20.8$ & .78 \\
\hline Alkaline phosphatase (U/L) & $104.8 \pm 119.4$ & $152.0 \pm 388.7$ & .43 \\
\hline \multicolumn{4}{|l|}{ Aspartate aminotransferase (quartiles, U/L) } \\
\hline $1(\leq 33 \mathrm{U} / \mathrm{L})$ & $23(19.3 \%)$ & $7(15.6 \%)$ & \\
\hline $2(34-60 \mathrm{U} / \mathrm{L})$ & $32(26.9 \%)$ & $10(22.2 \%)$ & \\
\hline $3(61-300 \mathrm{U} / \mathrm{L})$ & $34(28.6 \%)$ & $9(20 \%)$ & \\
\hline 4 (301-7879 U/L) & $30(25.2 \%)$ & $19(42.2 \%)$ & .32 \\
\hline \multicolumn{4}{|l|}{ Alanine aminotransferase (quartiles, U/L) } \\
\hline $1(\leq 23 \mathrm{U} / \mathrm{L})$ & $26(21.8 \%)$ & $9(20 \%)$ & \\
\hline $2(24-49 \mathrm{U} / \mathrm{L})$ & $32(26.9 \%)$ & $10(22.2 \%)$ & \\
\hline $3(50-216 \mathrm{U} / \mathrm{L})$ & $26(21.8 \%)$ & $8(17.7 \%)$ & \\
\hline 4 (217-7848 U/L) & $35(29.4 \%)$ & $18(40 \%)$ & .36 \\
\hline \multicolumn{4}{|l|}{ Gamma-glutamyltransferase (quartiles, U/L) } \\
\hline $1(\leq 25 \mathrm{U} / \mathrm{L})$ & $28(23.5 \%)$ & $7(15.6 \%)$ & \\
\hline $2(26-50 \mathrm{U} / \mathrm{L})$ & $30(25.2 \%)$ & $6(13.3 \%)$ & \\
\hline $3(51-86 \mathrm{U} / \mathrm{L})$ & $30(25.2 \%)$ & $17(37.8 \%)$ & \\
\hline $4(87-523 \mathrm{U} / \mathrm{L})$ & $31(26.1 \%)$ & $15(33.3 \%)$ & .55 \\
\hline Cholinesterase (mg/dL) & $4.54 \pm 1.81$ & $2.62 \pm 1.32$ & $<.001$ \\
\hline Lactate dehydrogenase (U/L) & $810.2 \pm 1292.6$ & $2135.6 \pm 5111.5$ & .1 \\
\hline Brain natriuretic peptide (ng/L) & $11738.0 \pm 13111.6$ & $9794.6 \pm 9958.1$ & .57 \\
\hline INR (PT) & $1.36 \pm 0.31$ & $1.74 \pm 0.60$ & $<.001$ \\
\hline Fibrinogen (mg/dL) & $411.7 \pm 170.6$ & $377.1 \pm 185.9$ & .29 \\
\hline Antithrombin III (\%) & $75.1 \pm 14.8$ & $51.8 \pm 10.4$ & $<.001$ \\
\hline \multicolumn{4}{|l|}{ Hemodynamic parameters at bridging } \\
\hline Central venous pressure $(\mathrm{mm} \mathrm{Hg})$ & $16.7 \pm 5.3$ & $17.1 \pm 6.1$ & .50 \\
\hline Mean pulmonary pressure $(\mathrm{mm} \mathrm{Hg})$ & $29.3 \pm 9.9$ & $33.1 \pm 10.4$ & .042 \\
\hline Mean arterial pressure $(\mathrm{mm} \mathrm{Hg})$ & $67.0 \pm 12.0$ & $61.1 \pm 11.9$ & .005 \\
\hline PCWP, mm Hg & $22.4 \pm 6.6$ & $24.2 \pm 6.2$ & .14 \\
\hline Pulmonary pulsatility index (systPAP/CVP) & $2.52 \pm 1.7$ & $2.41 \pm 1.2$ & .60 \\
\hline CVP/PCWP ratio & $0.74 \pm 0.28$ & $0.76 \pm 0.31$ & .66 \\
\hline $\mathrm{CVP} / \mathrm{PCWP}$ ratio $>0.63$ & $63(52.9 \%)$ & $26(57.8 \%)$ & .58 \\
\hline Cardiac index ( $\mathrm{L} / \mathrm{m}^{2}$ body surface area) & $1.86 \pm 0.9$ & $1.73 \pm 0.7$ & .50 \\
\hline Vasoactive medication & $60(50.4 \%)$ & $19(42.2 \%)$ & .35 \\
\hline \multicolumn{4}{|l|}{ Dopamine } \\
\hline Dopamine dosage $(\mu / \mathrm{kg} / \mathrm{min})$ & $48(40.3 \%)$ & $17(37.8 \%)$ & \\
\hline$\leq 5 \mu / \mathrm{kg} / \mathrm{min}$ & $13(10.9 \%)$ & $5(11.1 \%)$ & \\
\hline $5-10 \mu / \mathrm{kg} / \mathrm{min}$ & $4(3.4 \%)$ & $1(2.2 \%)$ & .96 \\
\hline \multicolumn{4}{|l|}{$>10 \mu / \mathrm{kg} / \mathrm{min}$} \\
\hline Norepinephrine & $49(41.2 \%)$ & $22(48.9 \%)$ & .37 \\
\hline \multicolumn{4}{|l|}{ Norepinephrine dosage $(\mu / \mathrm{kg} / \mathrm{min})$} \\
\hline$\leq 0.1 \mu / \mathrm{kg} / \mathrm{min}$ & $10(8.4 \%)$ & $1(2.2 \%)$ & \\
\hline
\end{tabular}


TABLE 2. Continued

\begin{tabular}{|c|c|c|c|}
\hline & $\begin{array}{c}\text { No liver failure } \\
(\mathrm{n}=119 \text { patients })\end{array}$ & $\begin{array}{c}\text { ALF } \\
(n=\mathbf{4 5} \text { patients })\end{array}$ & $P$ value \\
\hline $1.1-0.5 \mu / \mathrm{kg} / \mathrm{min}$ & $33(27.7 \%)$ & $16(35.6 \%)$ & \\
\hline$>0.5 \mu / \mathrm{kg} / \mathrm{min}$ & $6(5.0 \%)$ & $5(11.1 \%)$ & .20 \\
\hline Epinephrine & $71(59.7 \%)$ & $34(75.6 \%)$ & .06 \\
\hline \multicolumn{4}{|c|}{ Epinephrine dosage $(\mu / \mathrm{kg} / \mathrm{min})$} \\
\hline$\leq 0.05 \mu / \mathrm{kg} / \mathrm{min}$ & $32(26.9 \%)$ & $10(22.2 \%)$ & \\
\hline $0.05-0.2 \mu / \mathrm{kg} / \mathrm{min}$ & $28(23.5 \%)$ & $19(42.2 \%)$ & \\
\hline$>0.2 \mu / \mathrm{kg} / \mathrm{min}$ & $11(9.2 \%)$ & $5(11.1 \%)$ & .08 \\
\hline Phenylephrine & $35(29.4 \%)$ & $15(33.3 \%)$ & .63 \\
\hline Inotrope medication & $68(57.1 \%)$ & $36(80.0 \%)$ & .007 \\
\hline
\end{tabular}

Moreover, antithrombin III remained a strong clinical parameter in addition to the MELD score and indicates clinical relevance to traditionally thought liver parameters such as bilirubin. In addition, the need for hemofiltration at MCS onset and a history of repeated episodes of cardiac decompensation were further associated with increased risk for development of ALF.

Antithrombin III is entirely produced by hepatocytes and plays a key role as an endogenous antithrombotic agent of coagulation by the inhibition of thrombin, a central procoagulatory factor with pleiotropic effect. Therefore, monitoring of antithrombin III activity is of exceptional importance in the setting of extracorporeal circulation.

Antithrombin III is a well-described predictive parameter for postoperative hepatic failure in patients undergoing liver resection. Mizuguchi and colleagues ${ }^{11}$ showed among 158 patients with hepatocellular carcinoma undergoing liver resection that antithrombin III was the most reliable parameter to monitor hepatic functional reserve and showed higher predictive accuracy than dynamic functional testing, such as indocyanine green retention rate. Another study proposed that diminishing antithrombin III activity was associated with impaired microcirculation within the liver and that this might be a further explanation for "backward congestion" and "forward ischemia" of the hepatic parenchyma. ${ }^{12,13}$

Antithrombin III also plays an important role in the prevention of apoptosis and ischemia-induced inflammatory response. ${ }^{14}$ In an in vivo ischemia-reperfusion model in rats, treatment with antithrombin III via the portal vein was associated with significantly reduced apoptosis and inflammation. ${ }^{13}$ Ostrovski and colleagues ${ }^{13}$ examined leucocyte rolling in a feline mesentery ischemia-reperfusion model and antithrombin III administration before ischemia reduced neutrophil rolling and adhesion during reperfusion and reduced vascular permeability by $50 \%$. Because antithrombin III could rapidly reverse thrombin-induced but not histamine-induced leucocyte rolling in human endothelium, it seems to have major potential to reduce systemic inflammatory response syndrome (SIRS) induced by MCS.

SIRS is a sepsis-like clinical activation of the immune system and is typical for end-stage prolonged cardiogenic shock. Antithrombin III levels are independent predictors

TABLE 3. Results of the multivariable logistic regression analysis to evaluate independent predictors for acute liver failure after implementation of mechanical circulatory support

\begin{tabular}{|c|c|c|c|c|}
\hline & Wald & $\mathbf{R R}$ & $\mathbf{9 5} \% \mathrm{CI}$ & $P$ value \\
\hline Inotropic medication & 0.21 & 2.0 & $0.1-42.1$ & .65 \\
\hline Repeated ( $\geq 3$ ) decompensation events & 4.0 & 6.7 & 1.1-43.0 & .046 \\
\hline Renal replacement therapy & 4.7 & 8.6 & $1.2-61.2$ & .031 \\
\hline $\mathrm{pH}$ & 1.5 & 0.002 & $0.0-42.8$ & .22 \\
\hline Total bilirubin (mg/dL) & 0.8 & 1.3 & $0.76-2.1$ & .37 \\
\hline Lactate $(\mathrm{mg} / \mathrm{dL})$ & 1.03 & 0.99 & $0.98-1.008$ & .31 \\
\hline Antithrombin III (\%) & 11.8 & 0.84 & $0.77-0.93$ & .001 \\
\hline Cholinesterase & 2.77 & 0.59 & $0.32-1.1$ & .1 \\
\hline Atrial fibrillation & 0.06 & 1.31 & $0.16-10.7$ & .80 \\
\hline Mean pulmonary pressure & 0.001 & 1.002 & $0.92-1.1$ & .97 \\
\hline Mean arterial pressure & 0.006 & 1.003 & $0.92-1.1$ & .94 \\
\hline International normalized ratio & 4.0 & 0.87 & $0.1-7.0$ & .87 \\
\hline
\end{tabular}

Bold indicates that repeated decompensation events, renal replacement therapy, and antithrombine III were independent predictors for the development of acute liver failure. $R R$, Rate ratio; $C I$, confidence interval. 
TABLE 4. Results of the multivariable logistic regression analysis with inclusion of the Model for End-Stage Liver Disease score to evaluate independent predictors for acute liver failure after implementation of mechanical circulatory support

\begin{tabular}{|c|c|c|c|c|}
\hline & Wald & $\mathbf{R R}$ & 95\% CI & $P$ value \\
\hline Inotropic medication & 0.71 & 2.0 & $0.22-42.1$ & .42 \\
\hline Repeated ( $\geq 3$ ) decompensation events & 3.4 & 7.5 & $0.9-63.7$ & .062 \\
\hline $\mathrm{pH}$ & 3.4 & 0.00 & $0.0-2.2$ & .065 \\
\hline MELD score & 10.5 & 1.45 & $1.2-1.8$ & .001 \\
\hline Lactate (mg/dL) & 2.1 & 0.99 & $0.97-1.004$ & .15 \\
\hline Antithrombin III activity (\%) & 4.6 & 0.89 & 0.80-0.99 & .031 \\
\hline Cholinesterase & 1.34 & 0.67 & $0.34-1.3$ & .25 \\
\hline Atrial fibrillation & 0.27 & 1.88 & $0.17-20.3$ & .60 \\
\hline Mean pulmonary pressure & 0.37 & 1.002 & $0.93-1.1$ & .55 \\
\hline Mean arterial pressure & 0.001 & 1.0 & $0.91-1.1$ & .98 \\
\hline
\end{tabular}

Bold indicates that the MELD score and antithrombine III were independent predictors for the development of acute liver failure. $R R$, Rate ratio; $C I$, confidence interval; $M E L D$, Model for End-Stage Liver Disease.

of outcome in patients with SIRS, and its depletion is an early marker for the development. ${ }^{15}$ As a consequence, antithrombin III is a highly specific and sensitive marker not only for liver synthesis but also for SIRS.

Liver failure, as a consequence of HF, may be a consequence of chronic passive congestion and results in cardiac cirrhosis from prolonged congestive HF ${ }^{16,17}$ However, the pathophysiology of ischemic hepatitis resulting from acute "forward" failure and low cardiac output is poorly understood and has attained little clinical interest in the setting of HF. ${ }^{18}$ Moreover, it is widely believed that ischemic hepatitis is a self-limiting disease resolving after causative treatment of HF.

The results of our study showed that this widely accepted paradigm has to be abandoned in patients with severe HF and cardiogenic shock supported with mechanical devices. Development of profound ALF was similar in patients with acute and chronic HF and in patients with cardiogenic shock after acute myocardial infarction.

Repeated cardiac decompensation was an independent predictor for the development of ALF, but serum aminotransferase levels have shown no value as a clinical instrument to detect or quantify the extent of preexisting liver damage in patients with end-stage HF. ${ }^{19,20}$ In patients with chronic congestive liver fibrosis and repeated decompensation events, the interpretation of aminotransferases might wrongly underestimate the amount of exact liver damage because of the limited number of vital hepatocytes "at risk." More sensitive parameters, such as antithrombin III, bilirubin, and cholinesterase, should be looked at rather than isolated observation of aminotransferases to predict ALF. ${ }^{20}$ Aminotransferase levels alone may not be sufficient to discriminate between preexisting hepatic damage and amount of hepatic deterioration caused by acute cardiac decompensation. ${ }^{11,20}$

In a clinical setting among 2198 patients undergoing aortic valve replacement, preoperative antithrombin III was a strong independent predictor of 30-day and 3 -month mortality, and the conclusion was that low antithrombin III levels might be an indicator for thromboembolic complications. ${ }^{21}$ In our study, markers such as bilirubin failed to show significant prediction for ALF. In the Candesartan in Heart Failure: Assessment of Reduction in Mortality and Morbidity study, however, total bilirubin was the strongest predictor of adverse outcome instead of aminotransferases. ${ }^{22}$ However, the Candesartan in Heart Failure: Assessment of Reduction in Mortality and Morbidity study did not include measurements of cholinesterase and antithrombin III.

Our study, together with previous findings from patients with cirrhosis of noncardiac origin, ${ }^{11-13}$ found that the measurement of antithrombin III might be of higher predictive value than the monitoring of prothrombin. We have clearly shown that antithrombin III is a potent,

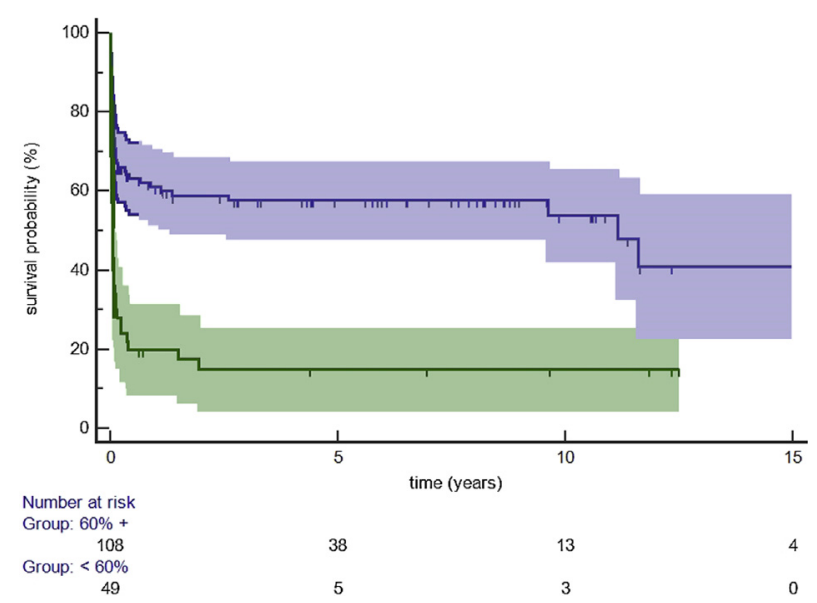

FIGURE 1. Kaplan-Meier survival analysis and corresponding 95\% CI of patients with end-stage HF undergoing MCS stratified for antithrombin cutoff levels. Group 1: antithrombin III levels $60 \%$ or more (blue lines). Group II: antithrombin III activity less than $60 \%$ at baseline (green lines). Log-rank: $P<.001$. 


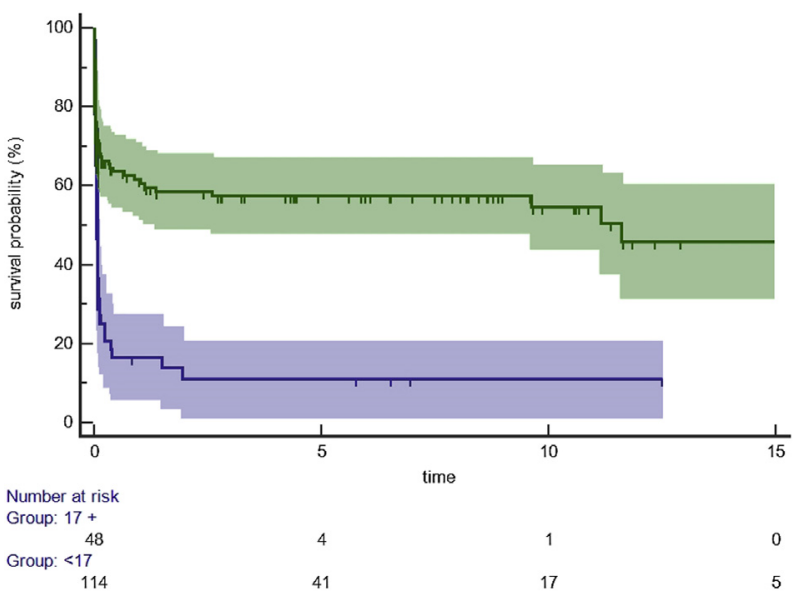

FIGURE 2. Kaplan-Meier survival analysis and corresponding 95\% CI of patients with end-stage HF undergoing MCS stratified for MELD score cutoff levels. Group 1: MELD score less than 17 (green lines). Group II: MELD score 17 or more (blue lines). Log-rank: $P<.001$.

highly sensitive and specific marker to predict ALF and SIRS in severe HF. MCS for patients with severe HF provides reasonable survival in patients with absence of or only mild multiorgan dysfunction. ${ }^{2,3,23}$ In patients with cardiogenic shock and preexisting severe deterioration of hepatic function, however, outcome after MCS is still poor. The "treat the heart, don't mind the kidney" policy in cardiorenal syndrome, however, is not applicable for the liver, and timely MCS or cardiac transplantation is the only salvage strategy to prevent ALF. ${ }^{24}$ To prevent ALF in patients undergoing MCS, we recommend serial antithrombin III measurement as standard of care in patients with decompensated HF, and attention should be paid to beginning depletion. Our results provide relevant clinical cutoffs for antithrombin III and the MELD score to indicate irreversibility of liver damage even when the liver is decompressed by MCS.

\section{Study Limitations}

The study has several limitations inherent in a retrospective study. Thus, one can argue that missing covariates may have confounded some of the trends seen in the current study. We did not study the influence of postoperative anticoagulation, but we are confident that none of the patients received antithrombin III before MCS. Because of the rarity of MCS in patients with cardiogenic shock and the singlecenter analysis, the reduced power may account for insignificant trends. Because liver biopsies or elastographic evaluation was not performed before MCS, we cannot rule out preexisting liver damage at baseline in patients with chronic forms of HF. There is no specific definition for liver-inheart-failure available yet; therefore, we have adopted the widely accepted King's College Criteria to indicate profound ALF.

\section{CONCLUSIONS}

Antithrombin III is a potent and reliable marker to predict ALF in patients with end-stage HF and should be implemented as routine clinical measure in severely ill patients with HF to detect patients at risk for irreversible hepatic failure more early and avoid MCS in patients with no reasonable chance of survival. This assessment may help to decide the optimal timing of MCS to reduce the burden of consecutive ALF during MCS. For the future, we should investigate whether antithrombin III administration may have a benefit in patients with severe cardiac decompensation. Substantial liver dysfunction is still the main source of morbidity and mortality during MCS, and further studies are warranted to investigate the potential role of antithrombin III in more stable patients with HF.

\section{Conflict of Interest Statement}

Authors have nothing to disclose with regard to commercial support.

The authors thank the perfusionists in our department: Hannes Engl, Anton Jeller, Kathrin Ebert, Sigrid Egger, Robert Gruber, Peter Müssiggang, Msc Florian Hiltpolt, and Helmut Olschnögger. Their professional assistance in preparing and maintaining the extracorporeal assist devices and the excellent documentation of preoperative and intraoperative data enabled us to perform this study.

\section{References}

1. Yancy CW, Jessup M, Bozkurt B, Butler J, Casey DE, Drazner MH, et al. 3013 ACCF/AHA guideline for the management of heart failure: a report of the American College of Cardiology Foundation/American Heart Association Task Force on practice guidelines. Circulation. 2013;15:e240-319.

2. Pagani FD, Lynch W, Swaniker F, Dyke DB, Bartlett R, Koelling T, et al. Extracorporeal life support to left ventricular assist device bridge to heart transplantation. Circulation. 1999;100:II-206-10.

3. Hoefer D, Ruttmann E, Poelzl G, Kilo J, Hoermann C, Margreiter R, et al. Outcome evaluation of the bridge-to-bridge concept in patients with cardiogenic shock. Ann Thorac Surg. 2006;82:28-33.

4. Metra M, Davison B, Bettari L, Sun H, Edwards C, Lazzarini V, et al. Is worsening renal function an ominous prognostic sign in patients with acute heart failure? The role of congestion and its interaction with renal function. Circ Heart Fail. 2012;5:54-62.

5. Metra M, Cotter G, Gheorghiade M, Dei Cas D, Voors AA. The role of the kidney in heart failure. Eur Heart J. 2012;33:2135-43.

6. Nikolaou M, Parissis J, Yilmaz B, Seronde MF, Kivikko Laribi S, PaugamBurtz C, et al. Liver function abnormalities, clinical profile, and outcome in acute decompensated heart failure. Eur Heart J. 2013;34:742-9.

7. Bart BA, Goldsmith SR, Lee KL, Givertz MM, O'Connor C, Bull DA, et al; for the Heart Failure Clinical Research Network. Ultrafiltration in decompensated heart failure with cardiorenal syndrome. N Engl J Med. 2012;367:2296-304.

8. Seeto RK, Fenn B, Rockey DC. Ischemic hepatitis: clinical presentation and pathogenesis. Am J Med. 2000;109:109-13.

9. Naschitz JE, Slobodin G, Lewis RJ, Zuckerman E, Yeshurun D. Heart diseases affecting the liver and liver diseases affecting the heart. Am Heart J. 2000;140: $111-20$.

10. O'Grady J, Alexander G, Hayllar K, Williams R. Early indicators of prognosis in fulminant hepatic failure. Gastroenterology. 1989;97:439-45.

11. Mizuguchi T, Kawamoto M, Meguro M, Son S, Nakamura Y, Harada K, et al. Serum antithrombin III level is well correlated with multiple indicators for assessment of liver function and diagnostic accuracy for predicting postoperative liver failure in hepatocellular carcinoma patients. Hepatogastroenterology. 2012; 59:551-7. 
12. Isik S, Tuncyurek P, Zengin NI, Demirbag AE, Atalay F, Yilmaz S, et al. Antithrombin prevents apoptosis by regulating inflammation in the liver in a model of cold ischemic/warm reperfusion injury. Hepatogastroenterology. 2012;59:453-7.

13. Ostrovski L, Woodman RC, Payne D, Teoh D, Kubes P. Antithrombin III prevents and rapidly reverses leucocyte recruitment in ischemia/reperfusion. Circulation. 1997:96:2302-10.

14. Inthorn D, Hoffmann JN, Hartl WH, Mühlbayer D, Jochum M. Antithrombin III supplementation in severe sepsis: beneficial effects on organ dysfunction. Shock. 1997;8:328-34.

15. Dhainaut JF, Marin N, Mignon A, Vinsonneau C. Hepatic response to sepsis: interaction between coagulation and inflammatory processes. Crit Care Med. 2001;29:S42-7.

16. Arcidi JM, Moore GW, Hutchins GM. Hepatic morphology in cardiac dysfunction. A clinicopathologic study of 1000 subjects at autopsy. Am J Pathol. 1981; 104:159-66.

17. Lam CSP, Lyass A, Kraigher-Krainer E, Massaro JM, Lee DS, Ho JE, et al. Cardiac dysfunction and noncardiac dysfunction as precursors of heart failure with reduced and preserved ejection fraction in the community. Circulation. 2011;124:24-30.

18. Denis C, De Kerguennec C, Bernuau J, Beauvais F, Cohen SA. Acute hypoxic hepatitis ("liver shock"): still a frequently overlooked cardiologic diagnosis. Eur J Heart Fail. 2004;6:561-5.

19. Ruttmann E, Brant LJ, Concin H, Diem G, Rapp K, Ulmer H, Vorarlberg Health Monitoring and Promotion Study Group. Gamma-glutamyltransferase as a risk factor for cardiovascular disease mortality: an epidemiological investigation in a cohort of 163,944 Austrian adults. Circulation. 2005;112:2130-7.
20. Poelzl G, Ess M, Mussner-Seeber C, Pachinger O, Frick M, Ulmer H. Liver dysfunction in chronic heart failure: prevalence, characteristics and prognostic significance. Eur J Clin Invest. 2012;42:153-63.

21. Florath I, Albert A, Hassanein W, Arnrich B, Rosendahl U, Ennker IC, et al. Current determinants of 30-day and 3-month mortality in over 2000 aortic valve replacements: impact of routine laboratory parameters. Eur J Cardiothorac Surg. 2006;30:716-21.

22. Allen LA, Felker GM, Pocock S, McMurray JJV, Pfeffer MA, Swedberg K, et al. For the CHARM investigators. Liver function abnormalities and outcome in patients with chronic heart failure: data from the Candesartan in Heart Failure: Assessment of Reduction in Mortality and Morbidity (CHARM) program. Eur J Heart Fail. 2009; 11:170-7.

23. Russell SD, Rogers JG, Milano CA, Dyke DB, Pagani FD, Aranda JM, et al; for the HeartMate II Clinical Investigators. Renal and hepatic function improve in in advanced heart failure patients during continuous-flow support with the HeartMate II left ventricular assist device. Circulation. 2009;120: 2352-7.

24. Ruggenenti P, Remuzzi G. Worsening kidney function in decompensated heart failure: treat the heart, don't mind the kidney. Eur Heart J. 2011;32:2476-8.

Key Words: cardiogenic shock, acute liver failure, mechanical circulatory support, extracorporeal membrane oxygenation

Readers who found these articles interesting may also like to read the following papers found in recent and future issues of our sister publications, Seminars in Thoracic and Cardiovascular Surgery and Operative Techniques in Thoracic and Cardiovascular Surgery!

\section{Acquired: Cardiopulmonary Transplantation and Mechanical Circulatory Support}

Rotary Blood Pumps as Long-Term Mechanical Circulatory Support: A Review of a 15-Year Berlin Experience. Roland Hetzer. Semin Thoracic Surg 2016:12-23.

Insights and Perspectives into Durable Mechanical Circulatory Support with Continuous Flow Technology from the Deutsches Herzzentrum Berlin. Francis D. Pagani. Semin Thoracic Surg 2016:24-25.

Vasodilatory Shock After Ventricular Assist Device Placement: A Bench to Bedside Review. John Baer. Semin Thoracic Surg 2016:238-244.

A Decade of Experience With Continuous-Flow Left Ventricular Assist Devices. Ranjit John. Semin Thoracic Surg 2016:363-374.

The Sky is Not Falling: Improving Results With the HeartMate 2 Continuous-Flow Left Ventricular Assist Device. Vivek Rao. Semin Thoracic Surg 2016:376-377.

Minimally Invasive Implantation: The Procedure of Choice! Jan D. Schmitto. Oper Tech Thorac Cardiovasc 2016:60-73. 